\title{
Evaluation Method of Immediate Effect of Local Vibratory Stimulation on Proprioceptive Control Strategy: A Pilot Study
}

\author{
Yohei Ito ${ }^{1}$, Keitaro Kawai ${ }^{2}$, Yoshifumi Morita ${ }^{1, *}$, Tadashi Ito ${ }^{3,4} \mathbb{D}$, Kazunori Yamazaki ${ }^{5}$, Yoshiji Kato ${ }^{6}$ \\ and Yoshihito Sakai ${ }^{7}$
}

check for updates

Citation: Ito, Y.; Kawai, K.; Morita, Y.; Ito, T.; Yamazaki, K.; Kato, Y.; Sakai, Y. Evaluation Method of Immediate Effect of Local Vibratory Stimulation on Proprioceptive Control Strategy: A Pilot Study. Electronics 2021, 10, 341. https://doi.org/10.3390/ electronics10030341

Academic Editor: Nicola Lopomo Received: 20 December 2020

Accepted: 27 January 2021

Published: 1 February 2021

Publisher's Note: MDPI stays neutral with regard to jurisdictional claims in published maps and institutional affiliations.

Copyright: (C) 2021 by the authors. Licensee MDPI, Basel, Switzerland. This article is an open access article distributed under the terms and conditions of the Creative Commons Attribution (CC BY) license (https:// creativecommons.org/licenses/by/ $4.0 /)$.
1 Department of Electrical and Mechanical Engineering, Graduate School of Engineering, Nagoya Institute of Technology, Nagoya 466-8555, Japan; y.ito.359@nitech.jp

2 Department of Electrical and Mechanical Engineering, Nagoya Institute of Technology, Nagoya 466-8555, Japan; k.kawai.750@nitech.jp

3 Three-Dimensional Motion Analysis Room, Aichi Prefectural Mikawa Aoitori Medical and Rehabilitation Center for Developmental Disabilities, Okazaki 444-0002, Japan; sanjigen@mikawa-aoitori.jp

4 Department of Physical Therapy, Graduate School of Medicine, Nagoya University, Nagoya, 461-8673, Japan

5 Faculty of Clinical Engineering, School of Medical Sciences, Fujita Health University, Toyoake 470-1192, Japan; ymzkk@fujita-hu.ac.jp

6 Department of Physical Therapy, Nagoya Heisei College of Nursing and Medical Care, Nagoya 464-0850, Japan; yoshi-waterfalls@cam.hi-ho.ne.jp

7 Department of Orthopedic Surgery, National Center for Geriatrics and Gerontology, Obu 474-8511, Japan; jsakai@ncgg.go.jp

* Correspondence: morita@nitech.ac.jp; Tel.: +81-52-735-5412

\begin{abstract}
Postural instability owing to poor proprioception is considered a main cause of low back pain and falls. However, the effect of local vibratory stimulation on a poor proprioceptor on proprioceptive control strategy has yet to be evaluated. Therefore, in this study, we proposed an evaluation method of the immediate effect on proprioceptive control strategies by applying local vibratory stimulation to the poor proprioceptor. First, using our device, we determined the poor proprioceptors in each of six elderly patients with non-specific low back pain. Furthermore, we applied local vibratory stimulation to the poor proprioceptor. Finally, we compared the proprioceptive control strategy before and after applying local vibratory stimulation. As a result, the proprioceptive control strategy improved for three patients with impaired muscle spindles that responded to a higher frequency $(p<0.05)$. Thus, the impaired proprioceptive control strategy caused by a decline in the muscle spindle responding to a higher frequency might be improved by local vibratory stimulation. Furthermore, it was shown that our developed device and protocol might be used to evaluate proprioceptive control strategies within multiple frequency ranges, as well as activate a poor proprioceptor based on diagnosis and improve the proprioceptive control strategies.
\end{abstract}

Keywords: proprioceptive control strategy; local vibratory stimulation; relative proprioceptive weighting ratio

\section{Introduction}

Poor proprioception is considered one of the main causes of decreased postural balance control in patients with non-specific low back pain (NSLBP) [1-6]. Proprioception is a deep sensation that perceives the position of each part of the body, the state of movement and muscle contraction, and resistance and mass applied to the body. In addition, the proprioceptor in the trunk and lower legs plays an important role in maintaining postural stability [7]. A proprioceptive control strategy in healthy adults with non-low back pain (NLBP) is thought to be a mixture of ankle strategy, which is more dependent on the proprioceptive signal from the lower legs, and hip strategy, which is more dependent on the proprioceptive signal from the trunk [8]. A proprioceptive control strategy refers to a postural 
control strategy in proprioceptive input during local vibratory stimulation. Meanwhile, patients with NSLBP are considered to have a change in proprioceptive control strategy, such as a reweighting of the proprioceptive signal from the trunk or lower legs [1,2,9]. Previous studies have reported that there tends to be an over-dependence on the mechanoreceptor input of the trunk while standing on a slightly unstable surface, which could increase the risk of postural instability in older adults with lumbar spondylosis [10-12]. In addition, it has been reported that older adults with lumbar spondylosis who are more likely to fall take an ankle strategy [13]. Therefore, proprioceptive control changes are related to low back pain and falls. In addition, a proprioceptive control strategy is thought to change owing to a decline in the proprioceptor.

Mechanical vibration is generally used to evaluate a proprioceptive control strategy [14-19]. It has been reported that illusory movement occurs by applying vibratory stimulation to proprioceptors such as muscle spindles [20]. For this reason, a proprioceptive control strategy is evaluated using the relative proprioceptive weighting ratio (RPW), which is the ratio of centre of pressure $(\mathrm{CoP})$ displacement that responds to local vibratory stimulation of the trunk and lower legs [1,9]. Proprioceptors include muscle spindles located in the skeletal muscle and the Vater-Pacini corpuscle located in the subcutaneous tissue and periosteum. Each proprioceptor has a vibration response frequency. Muscle spindles have a response frequency range of 30-100 Hz [21,22], whereas Vater-Pacini corpuscles have a response frequency range of $128-250 \mathrm{~Hz}[23,24]$.

Brumagne et al. reported that an accurate local vibratory stimulation of the lumbar multifidus muscle in patients with NSLBP at a frequency corresponding to the muscle spindle might improve the proprioceptive function [25]. Previous studies have also suggested that an improvement of the proprioceptive function associated with this local vibratory stimulation is effective not only for the trunk but also for the lower legs [16,26]. In addition, a previous study has reported that local vibratory stimulation can excite the proprioceptive and increase the muscle firing rate [27]. However, these studies evaluated only the effect of local vibratory stimulation on the proprioceptive function, and the effect on postural control in proprioceptive inputs has yet to be evaluated. Furthermore, these studies did not diagnose whether the proprioceptor was poor and applied the same frequency vibratory stimulation to all participants $[16,25,26]$. In other words, the effect on the proprioceptive control strategy when applying local vibratory stimulation to a poor proprioceptor has also not been evaluated to date. A previous study reported that vibratory stimulation for healthy proprioceptors might cause a decline in proprioceptive function [28]. Therefore, it is important to diagnose all proprioceptors and apply local vibratory stimulation to a poor proprioceptor. Thus, in this study, we proposed an evaluation method of the immediate effect on proprioceptive control strategies by applying local vibratory stimulation to a poor proprioceptor. Furthermore, we compared the proprioceptive control strategy before and after applying local vibratory stimulation to a poor proprioceptor.

\section{Materials and Methods}

\subsection{Participants}

This study was carried out over a period of 3 months (July-September 2020) in tandem with general clinical practice. All participants gave their informed consent for inclusion before participating in the study. The study was conducted in accord with the Declaration of Helsinki, and the protocol was approved by the Ethics Committee of the National Center for Geriatrics and Gerontology (IRB approval number 1405).

Six elderly individuals ( $\geq 65$ years in age, ranging $65-81 ; 5$ female and 1 male) were recruited. All participants were patients with NSLBP who lasted over 3 months and who visited the hospital in Aichi Prefecture for orthopaedic treatment. NSLBP was accurately diagnosed by a spine surgeon (Y.S.). NSLBP was evaluated using the visual analogue scale (VAS) and Roland-Morris disability questionnaire (RDQ). The VAS is presented as a 10-cm line, anchored by verbal descriptors, ranging from "no pain, 0 " to "worst imaginable pain, 10." The RDQ is a self-administered measure in which physical disability levels caused by 
NSLBP are reflected by higher numbers on a 24-point scale [29]. Patients with the following characteristics were excluded: paralysis, astasia, spinal cord tumour, spinal infection, and history of spinal surgery. The demographics of all individuals are presented in Table 1.

Table 1. Demographic characteristics and functional outcome of the patients.

\begin{tabular}{cc}
\hline Variables & NSLBP $(\mathbf{n}=\mathbf{6})$ \\
\hline Age, years & $71.7 \pm 7.0$ \\
Height, cm & $152.1 \pm 10.9$ \\
Weight, kg & $53.1 \pm 19.8$ \\
BMI, kg/m ${ }^{2}$ & $22.4 \pm 6.0$ \\
VAS, cm & $5.6 \pm 1.9$ \\
RDQ (score) & $12.8 \pm 5.0$ \\
\hline
\end{tabular}

NSLBP = non-specific low back pain; BMI = body mass index; VAS = visual analogue scale; RDQ = Roland-Morris disability questionnaire; $\mathrm{SD}=$ standard deviation. Data are presented as mean $\pm \mathrm{SD}$.

\subsection{Device}

Figure $1 \mathrm{a}, \mathrm{b}$ shows a diagnosis system used for evaluating the functional decline in proprioception. The system consists of a PC, an amplifier, four vibrators (1-inch Extended Range Loudspeaker, NSW1-205-8 A, Aurasound, Inc., Sanfe Fe Springs, CA, USA), three hook-and-loop fasteners, and a Wii Balance Board (Nintendo Co., Ltd., Kyoto, Japan). Two hook-and-loop fasteners with one vibrator were used for the lower left and right legs, and one hook-and-loop fastener with two vibrators was used for the left and right parts of the trunk.

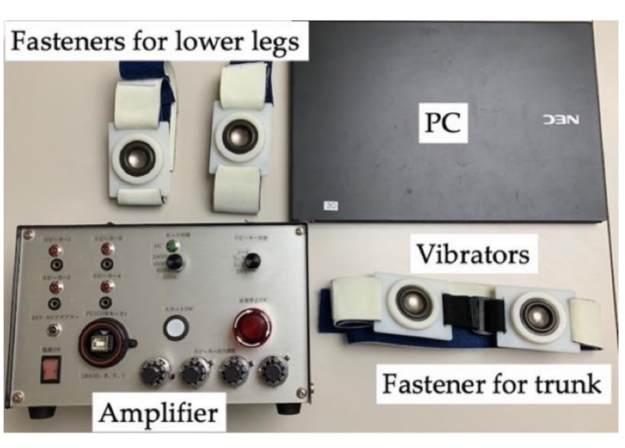

(a)

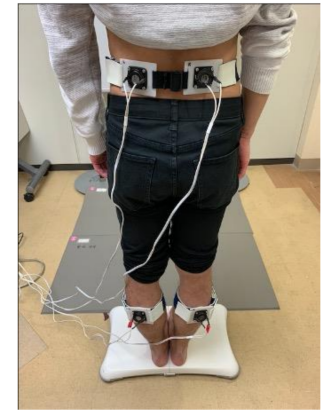

(b)

Figure 1. Diagnosis system for proprioceptive function: (a) Variable frequency local vibratory stimulation device; (b) Experimental setup for a participant.

Vibration signals were generated using a PC. Vibrations were then output from the vibrators as a mechanical local vibratory stimulation through the amplifier. In other previous studies, mechanical local vibratory stimulation with an amplitude of 0.4 to $1.0 \mathrm{~mm}$ was used as the proprioceptive input $[14,16,21]$. The vibratory stimulation amplitude is defined as the vertical displacement of the centre cap when the speaker is installed horizontally and facing upward. In addition, the maximum amplitude of our developed device, which can be output without distortion of the mechanical vibration at frequencies within $20-300 \mathrm{~Hz}$ is $0.8 \mathrm{~mm}$. Thus, the amplitude of the vibration was selected as $0.8 \mathrm{~mm}$ of a sinusoidal wave. Vibrators were attached to the hook-and-loop fasteners using holders and fixed to the muscle belly of the gastrocnemius and soleus muscles (GS) and to the lumbar multifidus (LM) muscles. When installing vibrators, the circumference of the fixed body locations was measured. Furthermore, the contact pressure was regulated by changing the length of the hook-and-loop fasteners made of rubber according to the circumference of the fixed body locations. The tension of hook-and-loop fasteners was adjusted to be always constant. The contact pressure was regulated to give a uniform intensity vibratory stimulation to all subjects. A Wii Balance Board was used as a gravicorder. The CoP was measured instead 
of the centre of gravity. The Wii Balance Board has been reported as a reliable and valid tool for assessing the standing balance [30-32]. It can acquire the time series data of CoP coordinates with a sampling frequency of $100 \mathrm{~Hz}$. Moreover, it is possible to save the CoP as CSV data by running the self-made CoP data collection software on a PC connected with the Wii Balance Board through Bluetooth.

The novelty of the vibratory stimulation device is that the frequency of the vibratory stimulation can be changed in accordance with time. In addition, this device can freely output the vibratory stimulation with a frequency of 20 to $300 \mathrm{~Hz}$. Previous studies have implied that the postural response induced by mechanical vibration varies with the applied vibration frequency even in one proprioceptor $[1,33]$. Thus, it is assumed that there are individual differences in response frequencies of proprioceptors. Therefore, it is considered necessary to give the vibratory stimulation to each proprioceptor over the entire response frequency range. In previous studies, constant frequency of vibratory stimulation was used for postural response measurements $[15,28,34]$. The device we have developed allows us to give the vibratory stimulation to each proprioceptor over the entire response frequency range. For this reason, it is considered that the posture response can be evaluated more accurately. In addition, this device can be used to evaluate the postural response to the vibratory stimulation in a specific response frequency range as in this study.

\subsection{Experimental Procedure}

The experiment was divided into three phases (Figure 2). The methods and processes used in each phase are presented below. It was confirmed that the participants experienced no pain during the measurements.

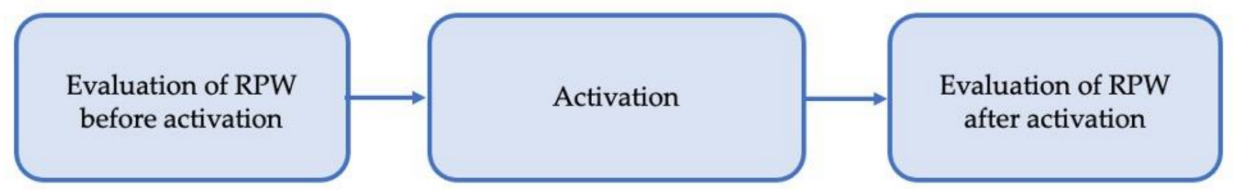

Figure 2. Each phase of the experiment.

\subsubsection{Evaluation of RPW before Activation}

During this phase, proprioceptive control strategies during sweep frequency (Figure 3) vibratory stimulation were evaluated by calculating the RPW. First, the experimental method is described. The CoP during postural sway was measured while the participants stood barefoot on the Wii Balance Board with their eyes closed and feet together. The participants were instructed to remain still and relaxed in a standing position with their arms hanging loosely at their sides. To prevent injury from a fall during measurements, two researchers stood on both sides of the subject who had both eyes closed. The researchers focused on whether the subject was likely to fall and provided support if the subject began falling. As the vibration frequency, a sweep frequency (Figure 3) developed by our group was used [33]. The vibration was continuously changed from 27 to $272 \mathrm{~Hz}$ (frequency ascend mode) or 272 to $27 \mathrm{~Hz}$ (frequency descend mode) for $60 \mathrm{~s}$, thus covering the response frequency ranges of the two proprioceptors. The relationships of the sweep frequency between frequency $f(t)$ and measurement time $t$ are shown in Equations (1) and (2). The coefficient a $(1 / \mathrm{s})$ was determined such that the frequencies at $t=15$ and $75 \mathrm{~s}$ were set to 27 and $272 \mathrm{~Hz}$ in frequency ascend mode, respectively. Thus, coefficient a $(1 / \mathrm{s})$ was found to be 0.03851 . Furthermore, the frequency descend mode had the same frequencies at $t=15$ and $75 \mathrm{~s}$ (272 and $27 \mathrm{~Hz}$, respectively).

$$
\begin{gathered}
f(t)=\left\{\begin{array}{c}
0(0 \leq t \leq 15) \\
27 \mathrm{e}^{\mathrm{a}(\mathrm{t}-15)}(15 \leq \mathrm{t} \leq 75)
\end{array} \quad\right. \text { (frequency ascend mode) } \\
\mathrm{f}(\mathrm{t})=\left\{\begin{array}{c}
0(0 \leq \mathrm{t} \leq 15) \\
27 \mathrm{e}^{\mathrm{a}(75-\mathrm{t})}(15 \leq \mathrm{t} \leq 75)
\end{array}\right. \text { (frequency descend mode) }
\end{gathered}
$$




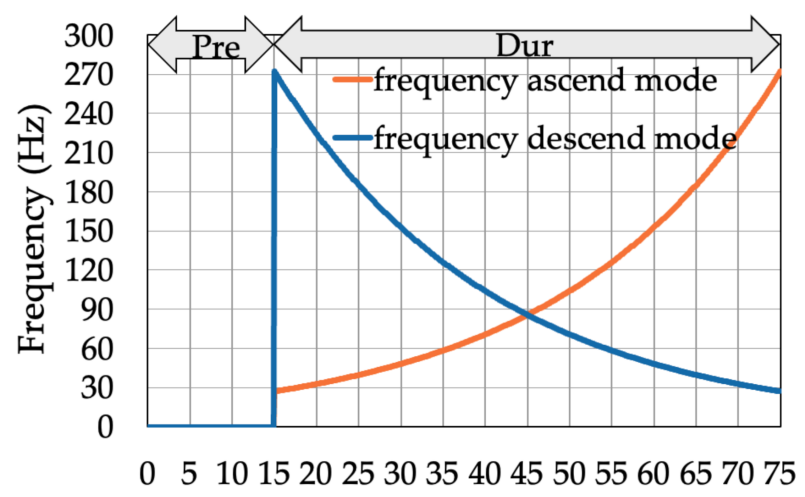

Figure 3. Sweep frequency of local vibratory stimulation.

The measurement procedure consisted of two conditions that provided vibratory stimulation, i.e., GS and LM. The time needed for one condition was $75 \mathrm{~s}$ and was divided into two sections. The first $15 \mathrm{~s}$ and last $60 \mathrm{~s}$ sections are referred to as Pre- and Dur-sections, respectively. During the Pre-section, the participants closed their eyes. In the Dur-section, local vibratory stimulation was applied to the GS or LM of the participants with their eyes closed. The ascend or descend sweep frequency mode was randomly determined for each subject. A rest interval of $60 \mathrm{~s}$ was maintained between the conditions. During this time, each participant sat in a chair and remained at rest.

Second, the data analysis method is explained. Proprioceptive control strategies were evaluated from the $\mathrm{CoP}$ data while the vibratory stimulation was applied. Furthermore, the $\mathrm{CoP}$ data divided the Dur-section into three evaluation sections ( $\mathrm{ESi}, \mathrm{i}=1,2,3)$ determined according to the frequency of vibratory stimulation and the response frequencies of the proprioceptors. Table 2 lists the names of each ES, the frequency of the local vibratory stimulation, and the corresponding proprioceptors. Each ES was determined from Equations (1) and (2) such that the measurement time for each section was $15 \mathrm{~s}$ because $15 \mathrm{~s}$ of data are generally used to evaluate the CoP displacement $[1,11,14]$.

Table 2. Lists of names of each ES, frequency of local vibratory stimulation, and corresponding proprioceptors.

\begin{tabular}{ccc}
\hline ES $_{\mathbf{i}}$ & Frequency $(\mathbf{H z})$ & Corresponding Proprioceptors \\
\hline ES $_{\mathbf{1}}$ & $30-53$ & Muscle spindles (lower frequency) \\
\hline ES $_{\mathbf{2}}$ & $56-100$ & Muscle spindles (higher frequency) \\
\hline ES $_{3}$ & $140-250$ & Vater-Pacini corpuscle \\
\hline
\end{tabular}

The CoP displacement in the anteroposterior direction was only considered because previous studies showed that a relationship exists between CoP displacement in an anteroposterior direction and the response of the proprioceptors to local vibratory stimulation [21]. Previous studies used the RPW and the root mean square (RMS) of the GS and LM as evaluation indexes to evaluate the proprioceptive control strategy and the magnitude of $\mathrm{CoP}$ in an anteroposterior direction $[1,11,14,33]$. RPW was calculated using Equation (3).

$$
\mathrm{RPW}_{\mathrm{i}}=\frac{\mathrm{RMS}_{\mathrm{i}}^{\mathrm{GS}}}{\mathrm{RMS}_{\mathrm{i}}^{\mathrm{GS}}+\mathrm{RMS}_{\mathrm{i}}^{\mathrm{LM}}} \times 100(\%)(\mathrm{i}=1,2,3)
$$

where subscript $\mathrm{i}$ is used to distinguish the ESs. The higher the value of $\mathrm{RPW}_{\mathrm{i}}$ from $50 \%$ to $100 \%$, the higher the reliability of the GS input. By contrast, the lower the value of $\mathrm{RPW}_{\mathrm{i}}$ is from $50 \%$ to $0 \%$, the higher the reliability of the LM input [14]. The value of $\mathrm{RMS}_{\mathrm{i}}$ indicates the effective value of the magnitude of $\mathrm{CoP}$ in an anteroposterior direction. In each $\mathrm{ES}$ in the Dur-section, the larger the RMS is, the higher the amount of transition of postural sway 
in the anteroposterior direction compared to that in the Pre-section. The values of RMS ${ }_{i}^{*}$ are calculated using the following:

$$
\begin{aligned}
\mathrm{RMS}_{1}^{*} & =\sqrt{\frac{1}{\mathrm{~N}} \sum_{\mathrm{n}=\mathrm{n}_{1}}^{\mathrm{n}_{2}}\left\{\mathrm{Y}_{\text {Dur }}^{*}(\mathrm{n})-\overline{\mathrm{Y}}_{\text {Pre }}^{*}\right\}^{2}} \\
\mathrm{RMS}_{2}^{*} & =\sqrt{\frac{1}{\mathrm{~N}} \sum_{\mathrm{n}=\mathrm{n}_{3}}^{\mathrm{n}_{4}}\left\{\mathrm{Y}_{\text {Dur }}^{*}(\mathrm{n})-\overline{\mathrm{Y}}_{\text {Pre }}^{*}\right\}^{2}} \\
\mathrm{RMS}_{3}^{*} & =\sqrt{\frac{1}{\mathrm{~N}} \sum_{\mathrm{n}=\mathrm{n}_{5}}^{\mathrm{n}_{6}}\left\{\mathrm{Y}_{\text {Dur }}^{*}(\mathrm{n})-\overline{\mathrm{Y}}_{\text {Pre }}^{*}\right\}^{2}}
\end{aligned}
$$

where $\mathrm{N}$ is the total number of samples of each ES; $\mathrm{n}$ is the number of data series; $\mathrm{Y}_{\text {Dur }}^{*}(\mathrm{n})$ is the $\mathrm{CoP}$ in the anteroposterior direction in the Dur-section; $\overline{\mathrm{Y}}_{\text {Pre }}^{*}$ is the mean value of $\mathrm{CoP}$ in the anteroposterior direction in the Pre-section; the superscript " $*$ " is used to distinguish the stimulation body locations, namely, the GS or LM; subscript numbers are used to distinguish the ESs. GS or LM is inserted into three superscripts of one equation and they are not mixed in one equation. In this case, $\mathrm{N}$ was equal to 1500 because all ESs were analysed in $15 \mathrm{~s}$ and the sampling frequency was $100 \mathrm{~Hz}$. Table 3 shows the number of data series corresponding to the start and end frequencies of ESi in the case of frequency ascend and descend modes. In the ascend and descend modes, the numbers of sampling series $n$ corresponding to measurement time $t$ were calculated using Equations (1) and (2) to obtain the start and end frequencies of each ES, respectively, as shown in Table 2. These values were calculated using MATLAB (MathWorks, Inc., Natick, MA, USA).

Table 3. Numbers of data series corresponding to the start and end frequencies of $\mathrm{ES}_{\mathrm{i}}$.

\begin{tabular}{ccccc}
\hline ES $_{\mathbf{i}}$ & $\begin{array}{c}\text { Number of } \\
\text { Data Series }\end{array}$ & $\begin{array}{c}\text { Frequency } \\
\text { Ascend Mode }\end{array}$ & $\begin{array}{c}\text { Frequency } \\
\text { Descend Mode }\end{array}$ & $\begin{array}{c}\text { Corresponding } \\
\text { Frequency (Hz) }\end{array}$ \\
\hline \multirow{2}{*}{$\mathrm{ES}_{1}$} & $\mathrm{n}_{1}$ & 1750 & 7250 & 30 \\
& $\mathrm{n}_{2}$ & 3250 & 5750 & 53 \\
\hline \multirow{2}{*}{$\mathrm{ES}_{2}$} & $\mathrm{n}_{3}$ & 3400 & 5600 & 56 \\
& $\mathrm{n}_{4}$ & 4900 & 4100 & 100 \\
\hline \multirow{2}{*}{$\mathrm{ES}_{3}$} & $\mathrm{n}_{5}$ & 5780 & 3220 & 140 \\
& $\mathrm{n}_{6}$ & 7280 & 1720 & 250 \\
\hline
\end{tabular}

ES $=$ evaluation sections; $\mathrm{n}=$ the number of data series. The subscript numbers of ES are indicated as follows: 1 = muscle spindles (lower frequency), from 30 to $53 \mathrm{~Hz} ; 2=$ muscle spindles (higher frequency), from 56 to $100 \mathrm{~Hz} ; 3$ = Vater-Pacini corpuscle, from 140 to $250 \mathrm{~Hz}$.

\subsubsection{Activation}

During this phase, we determined the poor proprioceptor and applied local vibratory stimulation to the determined poor proprioceptor. First, the method used to determine the poor proprioceptor is explained. The poor proprioceptors in each of the six elderly patients with NSLBP were determined based on the RPW of 60 healthy adults (Supplemental Tables S1 and S2). First, the difference between the measured value of RPW for elderly patients with NSLBP and the mean value of $\mathrm{RPW}_{\mathrm{i}}$ for healthy adults was calculated using Equation (7).

$$
\Delta \mathrm{RPW}_{\mathrm{i}}=\mathrm{RPW}_{\mathrm{i}}-\overline{\mathrm{RPW}}_{\mathrm{i}}^{\mathrm{H}}
$$

where subscript $i$ is used to distinguish the ESs, $R W_{i}$ is the measured value for elderly patients with NSLBP, and $\overline{R P W}_{i}^{\mathrm{H}}$ is the mean value of $\mathrm{RPW}_{\mathrm{i}}$ for healthy adults. Second, the absolute value of $\triangle \mathrm{RPW}_{\mathrm{i}}\left(\left|\Delta \mathrm{RPW}_{\mathrm{i}}\right|\right)$ was calculated and the ES with the largest value of $\left|\triangle \mathrm{RPW}_{\mathrm{i}}\right|$ out of the three ESs was defined as a poor proprioceptor because elderly patients with NSLBP are considered to change the RPW $[1,2,9]$. The closer the value of $\left|\Delta R P W_{i}\right|$ is 
to zero, the closer it is to the proprioceptive control strategy of healthy adults, indicating that there is no problem with the proprioceptive control strategy. Furthermore, when $\triangle R P W_{i}$ was greater than zero, it was judged that the proprioceptor in the trunk declined because it was more dependent on the proprioceptive signal from the lower legs compared with that of a healthy adult. By contrast, when $\triangle R P W_{i}$ was less than zero, it was judged that the proprioceptor in the lower legs was declined because it is more dependent on the proprioceptive signal from the trunk compared with healthy adults. In previous studies, it was considered that the proprioceptors of the GS are relatively declined than the LM when hip strategy is taken [11]. Similarly, it was considered that the proprioceptors of the LM are relatively declined than the GS when ancle strategy is taken. In this study, we focused on patients with either GS or LM declined and determined the one with relatively declined proprioceptor as the poor proprioceptor.

Second, the method used to apply local vibratory stimulation to the poor proprioceptor is explained. The local vibratory stimulation was applied to the poor proprioceptor for $1 \mathrm{~min}$ because a $1 \mathrm{~min}$ vibration was used to evaluate the effect of vibration in a previous study [34]. Patients with NSLBP were instructed to remain still and relaxed in a sitting position. The vibration frequency (Figure 4) was used to cover the response frequency ranges of the poor proprioceptor. Based upon which proprioceptor is declined, the relationships between frequency $f(t)$ and measurement time $t$ are shown in Equations (8)-(10), respectively. As shown in Figure 4, the frequency of the vibratory stimulation rises in $30 \mathrm{~s}$ and falls in $30 \mathrm{~s}$ to give the stimulation to each proprioceptor over the entire response frequency range. The sweep frequency was approximated as linear because the vibration that stimulates each frequency range in $30 \mathrm{~s}$ changes very slowly.

$$
\begin{aligned}
& \mathrm{f}(\mathrm{t})=\left\{\begin{array}{c}
0.7667 \mathrm{t}+30(0 \leq \mathrm{t} \leq 30) \\
-0.7667 \mathrm{t}+76(30 \leq \mathrm{t} \leq 60)
\end{array}\right. \\
& \text { fif } \left.\mathrm{ES}_{1} \text { is declined }\right)
\end{aligned}
$$

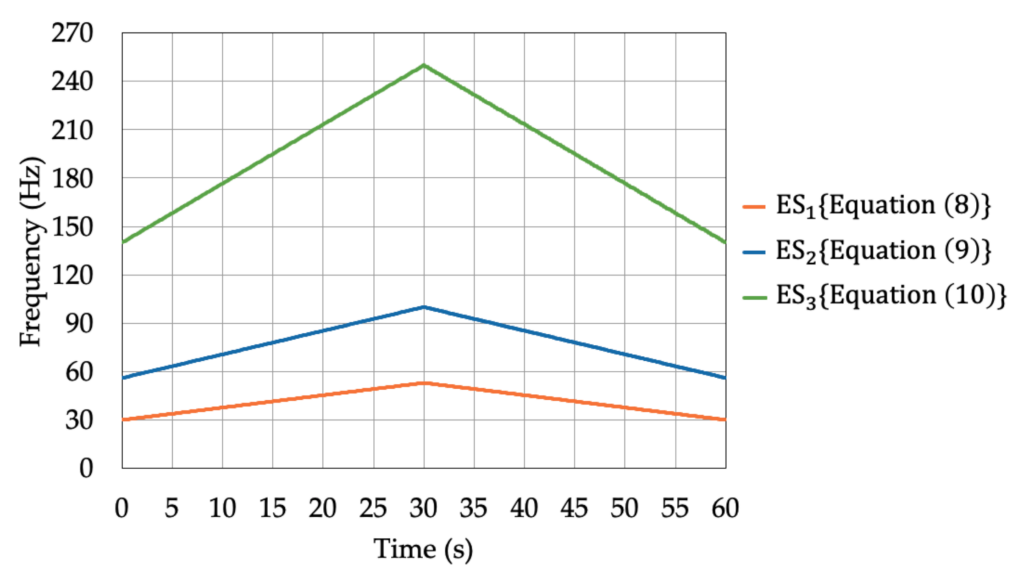

Figure 4. Frequency of local vibratory stimulation for the poor proprioceptor. ES = evaluation sections. The subscript numbers of ES are indicated as follows: $1=$ muscle spindles (lower frequency), from 30 to $53 \mathrm{~Hz} ; 2$ = muscle spindles (higher frequency), from 56 to $100 \mathrm{~Hz} ; 3$ = Vater-Pacini corpuscle, from 140 to $250 \mathrm{~Hz}$.

\subsubsection{Evaluation of RPW after Activation}

During this phase, proprioceptive control strategies during a specific sweep frequency (Figure 5) vibratory stimulation were evaluated by calculating the RPW. First, the exper- 
imental method is described. A rest interval of $2 \mathrm{~min}$ was maintained before evaluation of RPW after activation with reference to a previous study [34]. During this time, each participant sat in a chair and remained at rest. In addition, the RPW was measured again while the local vibratory stimulation was applied to the GS or LM along with the evaluation phase of RPW prior to activation. As the vibration frequency, a specific sweep frequency (Figure 5) was used to evaluate the RPW of only the poor proprioceptor. The vibration was continuously changed for $15 \mathrm{~s}$, covering the response frequency range of the poor proprioceptor. The reason why only poor proprioceptors were evaluated again is to reduce the physical burden on the subject by reducing the measurement time. The measurement time was shortened by $45 \mathrm{~s}$ from 75 to $30 \mathrm{~s}$ by evaluating only the poor proprioceptor. According to which proprioceptor is declined, the relationships of the sweep frequency between frequency $f(t)$ and measurement time $t$ are shown in Equations (11)-(16), respectively. The coefficient a (1/s) was found to be 0.03851 as well as Equations (1) and (2). In addition, either the ascend or descend sweep frequency mode was used. The mode was the same as the mode used in the phase of evaluation of the RPW before activation for each subject.

$$
\begin{aligned}
& f(t)=\left\{\begin{array}{c}
0(0 \leq t \leq 15) \\
27 e^{a(t-12.5)}(15 \leq t \leq 30)
\end{array} \quad \text { (frequency ascend mode if } E_{1}\right. \text { is declined) } \\
& \mathrm{f}(\mathrm{t})=\left\{\begin{array}{c}
0(0 \leq \mathrm{t} \leq 15) \\
27 \mathrm{e}^{\mathrm{a}(32.5-\mathrm{t})}(15 \leq \mathrm{t} \leq 30)
\end{array} \quad \text { (frequency descend mode if } \mathrm{ES}_{1}\right. \text { is declined) } \\
& f(t)=\left\{\begin{array}{c}
0(0 \leq t \leq 15) \\
27 e^{a(t+4)}(15 \leq t \leq 30)
\end{array} \quad \text { (frequency ascend mode if } \mathrm{ES}_{2}\right. \text { is declined) } \\
& f(t)=\left\{\begin{array}{c}
0(0 \leq t \leq 15) \\
27 e^{a(49-t)}(15 \leq t \leq 30)
\end{array} \quad \text { (frequency descend mode if } \mathrm{ES}_{2}\right. \text { is declined) } \\
& f(t)=\left\{\begin{array}{c}
0(0 \leq t \leq 15) \\
27 e^{a(t+27.8)}(15 \leq t \leq 30)
\end{array} \quad \text { (frequency ascend mode if } \mathrm{ES}_{3}\right. \text { is declined) } \\
& \mathrm{f}(\mathrm{t})=\left\{\begin{array}{c}
0(0 \leq \mathrm{t} \leq 15) \\
27 \mathrm{e}^{\mathrm{a}(72.8-\mathrm{t})}(15 \leq \mathrm{t} \leq 30)
\end{array} \quad \text { (frequency descend mode if } \mathrm{ES}_{3}\right. \text { is declined) }
\end{aligned}
$$

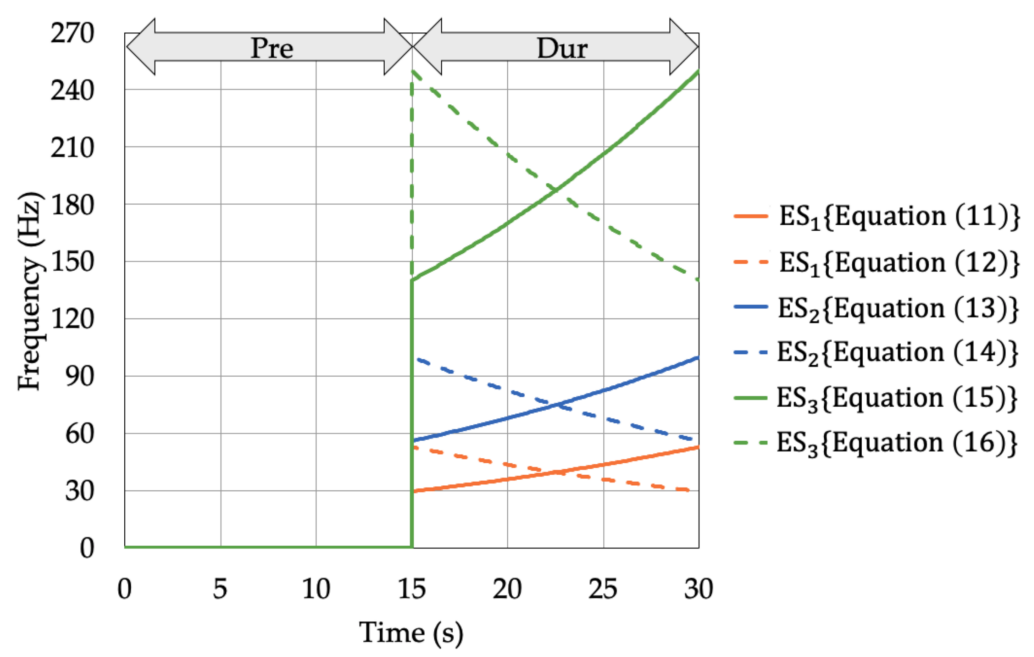

Figure 5. Specific sweep frequency of local vibratory stimulation. ES = evaluation sections. The subscript numbers of ES are indicated as follows: 1 = muscle spindles (lower frequency), from 30 to $53 \mathrm{~Hz} ; 2$ = muscle spindles (higher frequency), from 56 to $100 \mathrm{~Hz} ; 3$ = Vater-Pacini corpuscle, from 140 to $250 \mathrm{~Hz}$. 
Second, the data analysis method is described. Here, $\mathrm{RPW}_{\mathrm{i}}$ and $\triangle \mathrm{RPW} \mathrm{W}_{\mathrm{i}}$ are calculated using Equations (3) and (7), respectively. In addition, the RMS is calculated using Equation (17).

$$
\mathrm{RMS}_{\mathrm{i}}^{*}=\sqrt{\frac{1}{\mathrm{~N}} \sum_{\mathrm{n}=\mathrm{n}_{7}}^{\mathrm{n}_{8}}\left\{\mathrm{Y}_{\text {Dur }}^{*}(\mathrm{n})-\overline{\mathrm{Y}}_{\mathrm{Pre}}^{*}\right\}^{2}},
$$

where the subscript $\mathrm{i}$ is used to distinguish the ES of the poor proprioceptor, $\mathrm{N}$ is the total sampling number of each ES, $\mathrm{n}$ is the number of data series, $\mathrm{Y}_{\mathrm{Dur}}^{*}(\mathrm{n})$ is the CoP in the anteroposterior direction in the Dur-section; $\overline{\mathrm{Y}}_{\mathrm{Pre}}^{*}$ is the mean value of $\mathrm{CoP}$ in the anteroposterior direction in the Pre-section; the superscript " $*$ " is used to distinguish the stimulation body locations, namely, the GS or LM. GS or LM is inserted into three superscripts of one equation and they are not mixed in one equation. In this case, $\mathrm{N}$ was equal to 1500 because all ESs were analysed in $15 \mathrm{~s}$ and the sampling frequency was $100 \mathrm{~Hz}$. In addition, $\mathrm{n}_{7}$ and $\mathrm{n}_{8}$ were equal to 1500 and 3000 because the Dur-section was $15-30 \mathrm{~s}$. These values were calculated using MATLAB (MathWorks, Inc., Natick, MA, USA).

Finally, we compared the proprioceptive control strategy before and after applying local vibratory stimulation to the poor proprioceptor.

\subsection{Statistical Analysis}

All analyses were conducted using IBM SPSS statistical software (Version 25.0; IBM Co., Armonk, NY, USA). The frequency ascend and descend mode groups were combined into a population of $\mathrm{RPW}_{\mathrm{i}}$ for a statistical analysis to eliminate the order effects owing to the applied vibration. Data are expressed as mean values and standard deviations for patients with NSLBP. First, these data were analysed to investigate whether they were normally distributed using the Shapiro-Wilk test. Variable data of $\left|\Delta R P W_{i}\right|$ were compared before and after the local vibratory stimulation on the poor proprioceptor using the independent $t$-test if both the compared data were normally distributed. In the statistical analysis, $p<0.05\left(^{*}\right)$ was considered statistically significant.

\section{Results}

\subsection{Determination of Poor Proprioceptors}

Table 4 shows the results of $\triangle \mathrm{RPW}_{\mathrm{i}}$ of each patient with NSLBP and the determined poor proprioceptors. In addition, Figure 6 shows results of $\mathrm{CoP}$ displacement of the patient 6 in the anteroposterior direction before activation as representative results. A total of three out of six patients were judged to have impaired muscle spindles (higher frequency), two of which were judged to have impaired muscle spindles of the LM, and one was judged to have impaired muscle spindles of the GS. The remaining three patients were judged to have impaired Vater-Pacini corpuscles, two of which were judged to have impaired Vater-Pacini corpuscles of the LM, and one was judged to have impaired Vater-Pacini corpuscles of the GS.

Table 4. Results of $\triangle \mathrm{RPW}_{\mathrm{i}}$ of each patient with NSLBP and determined poor proprioceptors.

\begin{tabular}{ccccc}
\hline NSLBP & $\Delta \mathbf{R P W}_{\mathbf{1}}(\%)$ & $\Delta \mathbf{R P W}_{\mathbf{2}}(\%)$ & $\Delta \mathbf{R P W}_{\mathbf{3}}(\%)$ & Determined Poor Proprioceptor \\
\hline No. 1 & -4.9 & -16.1 & -5.0 & Muscle spindles (higher frequency) of GS \\
No. 2 & +6.7 & +9.5 & -7.1 & Muscle spindles (higher frequency) of LM \\
No. 3 & +0.4 & -0.8 & +12.3 & Vater-Pacini corpuscle of LM \\
No. 4 & +11.2 & +19.6 & -1.1 & Muscle spindles (higher frequency) of LM \\
No. 5 & +4.4 & +1.2 & -7.1 & Vater-Pacini corpuscle of GS \\
No. 6 & -29.2 & +18.3 & +29.7 & Vater-Pacini corpuscle of LM \\
\hline
\end{tabular}

NSLBP = non-specific low back pain; $\triangle \mathrm{RPW}_{\mathrm{i}}=$ difference between the measured value of $\mathrm{RPW}_{\mathrm{i}}$ for elderly patients with NSLBP and the mean value of $\mathrm{RPW}_{\mathrm{i}}$ for healthy adults. The subscript numbers indicate the following: 1 = muscle spindles (lower frequency), from 30 to $53 \mathrm{~Hz} ; 2$ = muscle spindles (higher frequency), from 56 to $100 \mathrm{~Hz} ; 3$ = Vater-Pacini corpuscle, from 140 to $250 \mathrm{~Hz}$. 


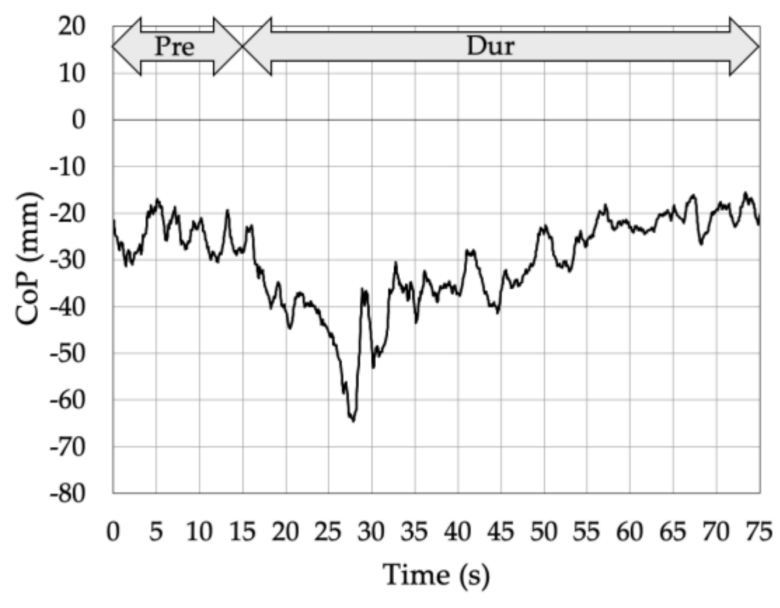

(a)

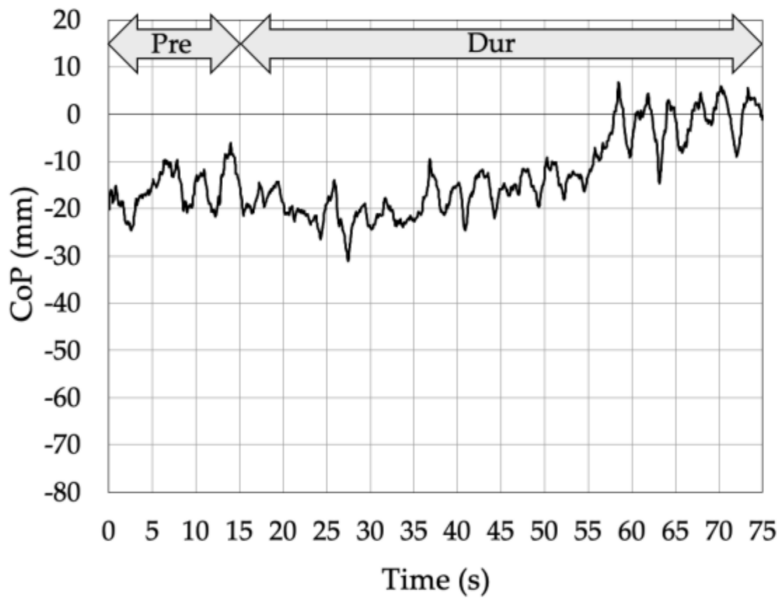

(b)

Figure 6. Results of CoP displacement of the patient 6 in the anteroposterior direction: (a) CoP displacement when the vibratory stimulation was applied to the GS; (b) CoP displacement when the vibratory stimulation was applied to the LM.

\subsection{Proprioceptive Control Strategy}

Table 5 and Figure 7 show a comparison of $\left|\Delta R P W_{i}\right|$ before and after applying vibration to the poor proprioceptor. For each evaluation index, the mean values and SDs are shown. For patients 1,2, and 4, who were given vibration to the muscle spindles (higher frequency), a comparison was made with $\left|\Delta R P W_{2}\right|$, and for patients 3,5 , and 6 , who were given vibration to the Vater-Pacini corpuscle, a comparison was made with $\left|\Delta \mathrm{RPW}_{3}\right|$. However, $\left|\Delta \mathrm{RPW}_{1}\right|$ was not compared because none of the patients were judged to have impaired muscle spindles (lower frequency). The results of $\mathrm{RPW}_{2}$ and $\mathrm{RPW}_{3}$ for each patient are shown in Figures 8 and 9.

Table 5. Results of $\left|\triangle R P W_{i}\right|$ of patients with NSLBP before and after applying local vibratory stimulation to the poor proprioceptor.

\begin{tabular}{ccccc}
\hline Variable & NSLBP & Before & After & P \\
\hline $\mid \Delta$ RPW $_{2} \mid(\%)$ & No. $1,2,4$ & $15.0 \pm 5.1$ & $6.8 \pm 3.2$ & $<0.05$ \\
$\mid \Delta$ RPW $_{3} \mid(\%)$ & No. $3,5,6$ & $16.3 \pm 11.8$ & $14.2 \pm 14.4$ & 0.607 \\
\hline
\end{tabular}

NSLBP = non-specific low back pain; $\left|\Delta \mathrm{RPW}_{\mathrm{i}}\right|=$ absolute difference between the measured value of $\mathrm{RPW}_{\mathrm{i}}$ for elderly patients with NSLBP and the mean value of $\mathrm{RPW}_{\mathrm{i}}$ for healthy adults. The subscript numbers indicate the following: 1 = muscle spindles (lower frequency), from 30 to $53 \mathrm{~Hz} ; 2$ = muscle spindles (higher frequency), from 56 to $100 \mathrm{~Hz} ; 3$ = Vater-Pacini corpuscle, from 140 to $250 \mathrm{~Hz}$.

As shown in Table 5 and Figure $7,\left|\Delta R P W_{2}\right|$ of the patients who were given vibration to the muscle spindles (higher frequency) became significantly smaller. By contrast, there was no significant change in $\left|\triangle \mathrm{RPW}_{3}\right|$ for the patients who were given vibration to the Vater-Pacini corpuscle. In addition, as shown in Figure 8, RPW 2 decreased for patients 2 and 4 , who were given vibration to the trunk, and increased for patient 1 , who was given vibration to the lower legs. However, as shown in Figure 9, RPW 3 decreased for patient 3, who was given vibration to the trunk, and no changes were observed in patients 5 and 6 . 


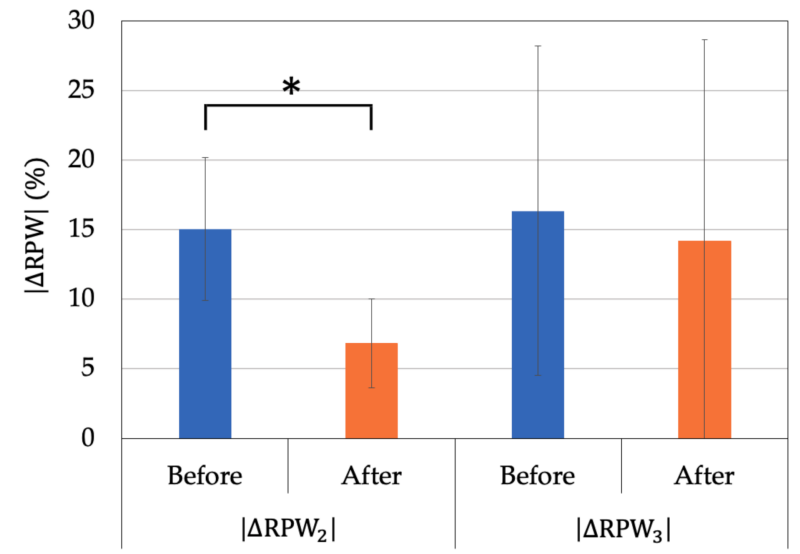

Figure 7. Results of $\left|\Delta R P W_{2}\right|$ and $\left|\Delta R P W_{3}\right|$ before and after applying local vibratory stimulation to the muscle spindles (higher frequency) and Vater-Pacini corpuscle, respectively. $\left|\Delta R P W_{2}\right|=$ absolute difference between the measured value of $\mathrm{RPW}_{2}$ for elderly patients with NSLBP and the mean value of $\mathrm{RPW}_{2}$ for healthy adults; $\left|\triangle \mathrm{RPW}_{3}\right|=$ absolute difference between the measured value of $\mathrm{RPW}_{3}$ for elderly patients with NSLBP and the mean value of $\mathrm{RPW}_{3}$ for healthy adults; $*=$ statistically significant at $p<0.05$.

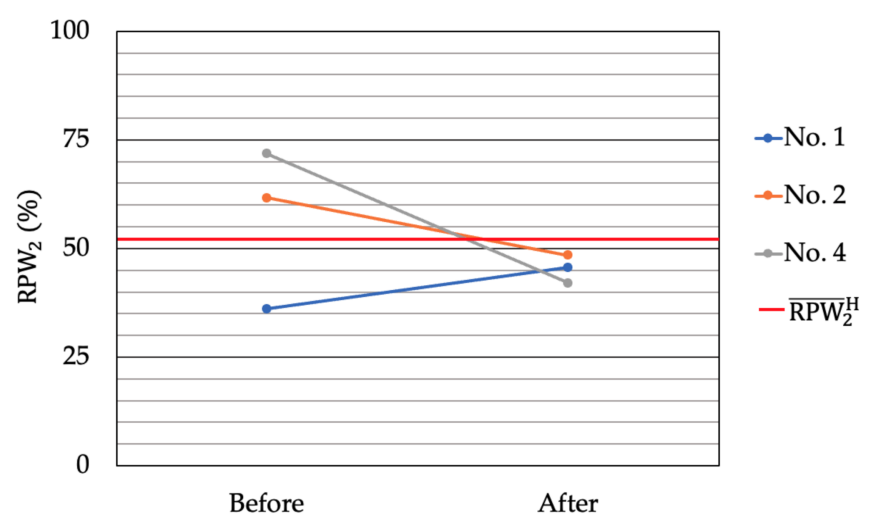

Figure 8. Results of $\mathrm{RPW}_{2}$ before and after applying local vibratory stimulation to the muscle spindles (higher frequency). $\mathrm{RPW}_{2}$ indicates the relative proprioceptive weighting ratio of muscle spindles (higher frequency), and $\overline{\mathrm{RPW}}_{2}^{\mathrm{H}}$ indicates the mean value of $\mathrm{RPW}$, for healthy adults (Supplemental Table S2).

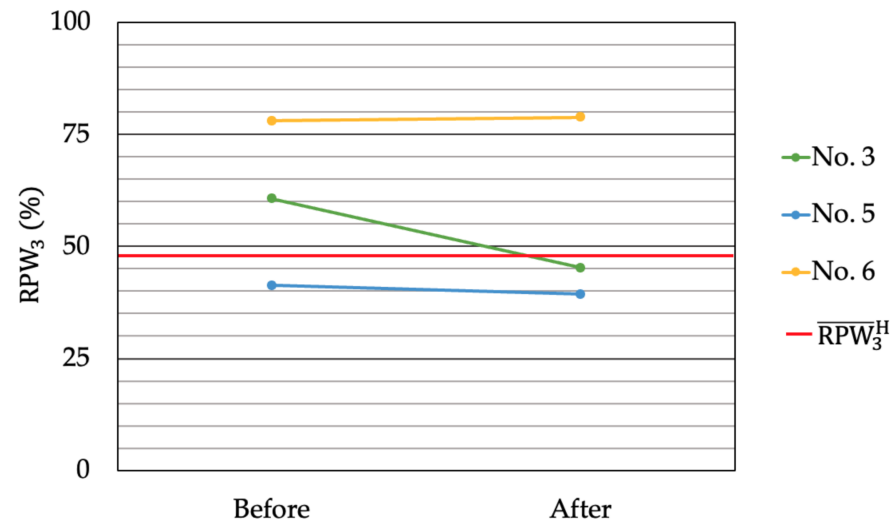

Figure 9. Results of $\mathrm{RPW}_{3}$ before and after applying local vibratory stimulation to the Vater-Pacini corpuscle. $\mathrm{RPW}_{3}$ indicates the relative proprioceptive weighting ratio of the Vater-Pacini corpuscle, and $\overline{\mathrm{RPW}}_{3}^{\mathrm{H}}$ indicates the mean value of $\mathrm{RPW}_{3}$ for healthy adults (Supplemental Table S2). 


\section{Discussion}

As our main finding in this study, patients with NSLBP showed improvements in the proprioceptive control strategy based on proprioceptive inputs from the muscle spindles that respond to a higher frequency. This improvement resulted from the activation of the poor proprioceptor after applying the local vibratory stimulation for $1 \mathrm{~min}$. As shown in Table 5 and Figure 7 , the significant reduction in $\left|\Delta R P W_{2}\right|$ indicates that the proprioceptive control strategy was improved by the local vibratory stimulation of the muscle spindles (higher frequency). In other words, the impaired proprioceptive control strategy caused by the decline in muscle spindles (higher frequency) might be improved by local vibratory stimulation. In addition, as shown in Figure 8, the decrease in $\mathrm{RPW}_{2}$ of patients 2 and 4, who were given vibration to the trunk, is thought to be due to the activation of the proprioceptor in the trunk. Similarly, the increase in $\mathrm{RPW}_{2}$ of patient 1 , who was given vibration to the lower legs, is thought to be due to the activation of the proprioceptor in the lower legs. These results are consistent with previous studies that reported that proprioceptors can be activated by vibration to the muscle spindle $[16,25,26]$. Previous studies have also reported that local vibratory stimulation can excite the proprioceptive and increase the muscle firing rate [27]. In this study, we found that these activations of proprioceptors by local vibratory stimulation might have an immediate effect on a proprioceptive control strategy. This finding is considered important because proprioceptive control strategies are associated with low back pain [11]. In addition, there is a possibility that the proprioceptive control strategy can be improved by applying vibratory stimulation to the muscle spindle, which responds to a higher frequency regardless of whether a hip or ankle strategy is taken.

Next, we considered the immediate effect on the proprioceptive control strategies by applying local vibratory stimulation to the Vater-Pacini corpuscle. As shown in Table 5 and Figure 7 , there was no change in $\left|\Delta \mathrm{RPW}_{3}\right|$ owing to a lack of change in $\mathrm{RPW}_{3}$ of patient 6 , whose proprioceptive control strategy was significantly different from that of healthy adults and that of patient 5 , whose proprioceptive control strategy was close to that of healthy adults. Meanwhile, patient 3 showed an improved proprioceptive control strategy. Therefore, local vibratory stimulation of the Vater-Pacini corpuscle may not have an immediate effect in those with an extremely impaired proprioceptive control strategy or in those with a non-impaired proprioceptive control strategy. A previous study reported that as the duration of the vibratory stimulation increases, the extent of activation of the proprioceptors may also increase [16]. Thus, a 1-min local vibratory stimulation might be too short for those with an extremely impaired proprioceptive control strategy. It might be possible to improve the proprioceptive control strategy by increasing the duration of the local vibratory stimulation.

To the best of our knowledge, this is the first study to evaluate the immediate effect on a proprioceptive control strategy when applying local vibratory stimulation to a poor proprioceptor. Previous studies have reported that local vibratory stimulation of the lumbar multifidus muscle in patients with NSLBP at a frequency corresponding to the muscle spindle might improve the proprioceptive function [25]. Previous studies have also suggested that an improvement of the proprioceptive function associated with this local vibratory stimulation is effective not only for the trunk but also for the lower legs $[16,26]$. In this study, we found that local vibratory stimulation might have an immediate effect on a proprioceptive control strategy. Specifically, the impaired proprioceptive control strategy caused by the decline in muscle spindles that respond to a higher frequency might be improved through a local vibratory stimulation. In addition, to our best knowledge, this is the first study to diagnose all proprioceptors and apply local vibratory stimulation to the poor proprioceptor. According to the diagnosis, three patients had impaired muscle spindles that responded to a high frequency, whereas three patients had impaired VaterPacini corpuscles. Furthermore, four patients $(1,2,3$, and 4$)$ out of the six patients showed an improved proprioceptive control strategy based on proprioceptive inputs from the poor proprioceptor after applying local vibratory stimulation to the poor proprioceptor. These results indicate that our developed device and protocol might be able to activate the poor 
proprioceptor based on diagnosis. A previous study reported that vibratory stimulation for healthy proprioceptors might cause a decline in proprioceptive function [28]. Therefore, it is important to diagnose all proprioceptors and apply local vibratory stimulation to a poor proprioceptor. We believe that our developed device and protocol will play an important role in the activation of poor proprioceptors when using local vibratory stimulation.

This study has a few limitations, including a small sample size of older patients with NSLBP. The number of subjects should therefore be increased, and the immediate effect on the proprioceptive control strategy should be evaluated by applying local vibratory stimulation to the poor proprioceptor. Second, the effect of proprioceptive improvement with respect to the NSLBP of the participants was not evaluated in this study. Assessing this could provide more information on the possible effects of NSLBP. In the future, we plan to verify whether improved proprioceptive control strategy can be maintained for a long time. In addition, we will verify the possibility of relieving low back pain by improving the impaired proprioceptive control strategy.

\section{Conclusions}

In this study, we proposed an evaluation method of the immediate effect on proprioceptive control strategies by applying local vibratory stimulation to the poor proprioceptor. Furthermore, we compared the proprioceptive control strategy before and after applying local vibratory stimulation to a poor proprioceptor. As a result, it was shown that an impaired proprioceptive control strategy caused by a decline in muscle spindle responding to a higher frequency might be improved through local vibratory stimulation. Furthermore, it was shown that our developed device and protocol might be used to evaluate proprioceptive control strategies within multiple frequency ranges, as well as activate a poor proprioceptor based on diagnosis and improve the proprioceptive control strategies. In the future, we plan to verify whether improved proprioceptive control strategy can be maintained for a long time. We will also verify the possibility of relieving low back pain by improving the impaired proprioceptive control strategy.

Supplementary Materials: The following are available online at https://www.mdpi.com/2079-929 2/10/3/341/s1, Table S1: Demographic characteristics and functional outcome of healthy adults, Table S2: Results of $\mathrm{RMS}_{1}{ }^{*}$ and $\mathrm{RPW}_{1}$ of healthy adults.

Author Contributions: Conceptualisation, Y.M. and Y.S.; methodology, Y.M.; software, Y.I. and K.K.; validation, T.I.; formal analysis, Y.I.; investigation, Y.I., K.K., T.I., K.Y. and Y.K.; resources, Y.M. and Y.S; data curation, Y.I. and K.K.; writing—original draft preparation, Y.I.; writing—review and editing, K.K., Y.M., T.I., K.Y., Y.K. and Y.S.; visualisation, Y.I.; supervision, Y.M.; project administration, Y.M. and Y.S.; funding acquisition, Y.S. All authors have read and agreed to the published version of the manuscript.

Funding: This research was funded by Geriatrics and Gerontology research and development cost, grant number 29-6. The APC was funded by Geriatrics and Gerontology research and development costs.

Institutional Review Board Statement: The study was conducted according to the guidelines of the Declaration of Helsinki, and approved by the Ethics Committee of the National Center for Geriatrics and Gerontology (IRB approval number 1405).

Informed Consent Statement: Informed consent was obtained from all subjects involved in the study.

Data Availability Statement: All of the relevant data are presented within the manuscript. All data are available from the authors on request.

Acknowledgments: The authors thank the staff, teachers, and principals in the Department of Orthopedic Surgery, National Center for Geriatric and Gerontology, and Nagoya Heisei College of Nursing and Medical Care for their help with the participant recruitment.

Conflicts of Interest: The authors declare no conflict of interest. 


\section{References}

1. Brumagne, S.; Cordo, P.; Verschueren, S. Proprioceptive Weighting Changes in Persons with Low Back Pain and Elderly Persons during Upright Standing. Neurosci. Lett. 2004, 366, 63-66. [CrossRef] [PubMed]

2. Brumagne, S.; Janssens, L.; Knapen, S.; Claeys, K.; Suuden-Johanson, E. Persons with Recurrent Low Back Pain Exhibit a Rigid Postural Control Strategy. Eur. Spine J. 2008, 17, 1177-1184. [CrossRef] [PubMed]

3. Brumagne, S.; Lysens, R.; Swinnen, S.; Verschueren, S. Effect of Paraspinal Muscle Vibration on Position Sense of the Lumbosacral Spine. Spine 1999, 24, 1328-1331. [CrossRef]

4. Janssens, L.; Brumagne, S.; Polspoel, K.; Troosters, T.; McConnell, A. The Effect of Inspiratory Muscles Fatigue on Postural Control in People with and Without Recurrent Low Back Pain. Spine 2010, 35, 1088-1094. [CrossRef] [PubMed]

5. Johanson, E.; Brumagne, S.; Janssens, L.; Pijnenburg, M.; Claeys, K.; Pääsuke, M. The Effect of Acute Back Muscle Fatigue on Postural Control Strategy in People with and Without Recurrent Low Back Pain. Eur. Spine J. 2011, 20, 2152-2159. [CrossRef]

6. Henry, S.M.; Hitt, J.R.; Jones, S.L.; Bunn, J.Y. Decreased Limits of Stability in Response to Postural Perturbations in Subjects with Low Back Pain. Clin. Biomech. 2006, 21, 881-892. [CrossRef]

7. Bloem, B.R.; Allum, J.H.; Carpenter, M.G.; Honegger, F. Is Lower Leg Proprioception Essential for Triggering Human Automatic Postural Responses? Exp. Brain Res. 2000, 130, 375-391. [CrossRef]

8. Mok, N.W.; Brauer, S.G.; Hodges, P.W. Hip Strategy for Balance Control in Quiet Standing Is Reduced in People with Low Back Pain. Spine 2004, 29, E107-E112. [CrossRef]

9. Claeys, K.; Brumagne, S.; Dankaerts, W.; Kiers, H.; Janssens, L. Decreased Variability in Postural Control Strategies in Young People with Non-Specific Low Back Pain Is Associated with Altered Proprioceptive Reweighting. Eur. J. Appl. Physiol. 2011, 111, 115-123. [CrossRef]

10. Ito, T.; Sakai, Y.; Yamazaki, K.; Igarashi, K.; Sato, N.; Yokoyama, K.; Morita, Y. Proprioceptive Change Impairs Balance Control in Older Patients with Low Back Pain. J. Phys. Ther. Sci. 2017, 29, 1788-1792. [CrossRef]

11. Ito, T.; Sakai, Y.; Morita, Y.; Yamazaki, K.; Igarashi, K.; Nishio, R.; Sato, N. Proprioceptive Weighting Ratio for Balance Control in Static Standing Is Reduced in Elderly Patients with Non-Specific Low Back Pain. Spine 2018, 43, 1704-1709. [CrossRef] [PubMed]

12. Ito, T.; Sakai, Y.; Ito, Y.; Yamazaki, K.; Morita, Y. Association between Back Muscle Strength and Proprioception or Mechanoreceptor Control Strategy in Postural Balance in Elderly Adults with Lumbar Spondylosis. Healthcare 2020, 8, 58. [CrossRef] [PubMed]

13. Ito, T.; Sakai, Y.; Nishio, R.; Ito, Y.; Yamazaki, K.; Morita, Y. Relationship Between Postural Stability and Fall Risk in Elderly People with Lumbar Spondylosis During Local Vibratory Stimulation for Proprioception: A Retrospective Study. Somatosens. Mot. Res. 2020, 37, 133-137. [CrossRef] [PubMed]

14. Brumagne, S.; Janssens, L.; Janssens, E.; Goddyn, L. Altered Postural Control in Anticipation of Postural Instability in Persons with Recurrent Low Back Pain. Gait Posture 2008, 28, 657-662. [CrossRef] [PubMed]

15. Goossens, N.; Janssens, L.; Pijnenburg, M.; Caeyenberghs, K.; Van Rompuy, C.; Meugens, P.; Sunaert, S.; Brumagne, S. Test-Retest Reliability and Concurrent Validity of an fMRI-Compatible Pneumatic Vibrator to Stimulate Muscle Proprioceptors. Multisens. Res. 2016, 29, 465-492. [CrossRef]

16. Capicíková, N.; Rocchi, L.; Hlavacka, F.; Chiari, L.; Cappello, A. Human Postural Response to Lower Leg Muscle Vibration of Different Duration. Physiol. Res. 2006, 55 (Suppl. 1), S129-S134.

17. Barbieri, G.; Gissot, A.S.; Fouque, F.; Casillas, J.M.; Pozzo, T.; Pérennou, D. Does Proprioception Contribute to the Sense of Verticality? Exp. Brain Res. 2008, 185, 545-552. [CrossRef]

18. Ceyte, H.; Cian, C.; Zory, R.; Barraud, P.A.; Roux, A.; Guerraz, M. Effect of Achilles Tendon Vibration on Postural Orientation. Neurosci. Lett. 2007, 416, 71-75. [CrossRef]

19. Thompson, C.; Bélanger, M.; Fung, J. Effects of Bilateral Achilles tendon Vibration on Postural Orientation and Balance during Standing. Clin. Neurophysiol. 2007, 118, 2456-2467. [CrossRef]

20. Roll, J.P.; Vedel, J.P. Kinaesthetic Role of Muscle Afferents in Man, Studied by Tendon Vibration and Microneurography. Exp. Brain Res. 1982, 47, 177-190. [CrossRef]

21. Pyykkö, I.; Jäntti, P.; Aalto, H. Postural Control in Elderly Subjects. Age Ageing 1990, 19, 215-221. [CrossRef] [PubMed]

22. Albert, F.; Bergenheim, M.; Ribot-Ciscar, E.; Roll, J.P. The Ia Afferent Feedback of a Given Movement Evokes the Illusion of the Same Movement When Returned to the Subject via Muscle Tendon Vibration. Exp. Brain Res. 2006, 172, 163-174. [CrossRef] [PubMed]

23. Kuroki, S.; Hagura, N.; Nishida, S.; Haggard, P.; Watanabe, J. Sanshool on the Fingertip Interferes with Vibration Detection in a Rapidly Adapting (RA) Tactile Channel. PLoS ONE 2016, 11, e0165842. [CrossRef] [PubMed]

24. Wu, G.; Ekedahl, R.; Stark, B.; Carlstedt, T.; Nilsson, B.; Hallin, R.G. Clustering of Pacinian Corpuscle Afferent Fibres in the Human Median Nerve. Exp. Brain Res. 1999, 126, 399-409. [CrossRef] [PubMed]

25. Brumagne, S.; Cordo, P.; Lysens, R.; Verschueren, S.; Swinnen, S. The Role of Paraspinal Muscle Spindles in Lumbosacral Position Sense in Individuals with and Without Low Back Pain. Spine 2000, 25, 989-994. [CrossRef] [PubMed]

26. Tjernström, F.; Fransson, P.A.; Hafström, A.; Magnusson, M. Adaptation of Postural Control to Perturbations-A Process That Initiates Long-Term Motor Memory. Gait Posture 2002, 15, 75-82. [CrossRef]

27. Burke, D.; Hagbarth, K.E.; Löfstedt, L.; Wallin, B.G. The Responses of Human Muscle Spindle Endings to Vibration of NonContracting Muscles. J. Physiol. 1976, 261, 673-693. [CrossRef] 
28. Boucher, J.A.; Normand, M.C.; Descarreaux, M. Trunk Isometric Force Production Parameters during Erector Spinae Muscle Vibration at Different Frequencies. J. Neuroeng. Rehabil. 2013, 10, 89. [CrossRef]

29. Roland, M.; Morris, R. A Study of the Natural History of Back Pain. Part I: Development of a Reliable and Sensitive Measure of Disability in Low-Back Pain. Spine 1983, 8, 141-144. [CrossRef]

30. Clark, R.A.; Mentiplay, B.F.; Pua, Y.H.; Bower, K.J. Reliability and Validity of the Wii Balance Board for Assessment of Standing Balance: A Systematic Review. Gait Posture 2018, 61, 40-54. [CrossRef]

31. Young, W.; Ferguson, S.; Brault, S.; Craig, C. Assessing and Training Standing Balance in Older Adults: A Novel Approach Using the "Nintendo Wii" Balance Board. Gait Posture 2011, 33, 303-305. [CrossRef] [PubMed]

32. Holmes, J.D.; Jenkins, M.E.; Johnson, A.M.; Hunt, M.A.; Clark, R.A. Validity of the Nintendo Wii®Balance Board for the Assessment of Standing Balance in Parkinson's Disease. Clin. Rehabil. 2013, 27, 361-366. [CrossRef] [PubMed]

33. Nishio, R.; Ito, Y.; Morita, Y.; Ito, T.; Yamazaki, K.; Sakai, Y. Investigation of the Functional Decline in Proprioceptors for Low Back Pain Using the Sweep Frequency Method. Appl. Sci. 2019, 9, 4988. [CrossRef]

34. Toosizadeh, N.; Ehsani, H.; Miramonte, M.; Mohler, J. Proprioceptive Impairments in High Fall Risk Older Adults: The Effect of Mechanical Calf Vibration on Postural Balance. Biomed. Eng. Online 2018, 17, 51. [CrossRef] 